\title{
Persistência do uraco em gato: relato de caso
}

\author{
[Urachal persistence in a cat: case report] \\ G.A.S. Aleixo, M. Souza, Z.F. Mendes, D. Baraúna Junior, J.E.B. Leite \\ A.P.M. Tenório, M.C.O.C. Coelho \\ Universidade Federal Rural de Pernambuco - Recife, PE
}

\begin{abstract}
RESUMO
Relata-se o caso de um gato que apresentava persistência do uraco, cujos principais sinais clínicos, iniciados apenas aos cinco meses de idade foram micção através da cicatriz umbilical, hiperemia da área circunvizinha e presença de uma fístula no centro do umbigo. A afecção foi diagnosticada mediante exames clínico, laboratorial, ultra-sonográfico e radiográfico, especialmente pela cistografia .
\end{abstract}

Palavras-chave: gato, persistência do úraco, vesícula urinária.

\begin{abstract}
It is reported a case of a cat presenting persistence of the urachal. The symptoms only began at five months of age. The diagnosis was confirmed by the clinical, laboratorial, ultrasonographic and radiographic exams, especially by the cystography.
\end{abstract}

Keywords: cat, urachal persistence, urinary vesicle

\section{INTRODUÇÃO}

O uraco é uma estrutura embrionária que comunica a vesícula urinária em desenvolvimento ao umbigo e saco alantóide (Waldron, 1998), para permitir que parte da urina fetal seja encaminhada para a placenta e, em seguida, eliminada juntamente com a urina materna (Lulich et al., 1997; Osborne et al., 1997).

$\mathrm{O}$ uraco regride à medida que se completa o desenvolvimento do feto. Ao nascimento ele perde a função (Lulich et al., 1997) e a urina passa a ser totalmente excretada pela uretra (Hansen, 1972; Osborne et al., 1997; Waldron, 1998). Na maioria dos animais, ao se fechar, forma-se uma cicatriz no ápice da vesícula urinária (Hansen, 1977). Em raros casos, o uraco

Recebido em 12 de janeiro de 2007

Aceito em 6 de junho de 2007

Endereço para correspondência (corresponding address)

Rua Conselheiro Portela, n. 130, apt. 1602 - Espinheiro 52020-030 - Recife, PE

E-mail: grazielle@yahoo.com pode permanecer aberto, resultando em anormalidades (McCrystal et al., 2001).

Em humanos, as patologias referentes ao não fechamento do uraco podem ser a persistência, divertículo vésico-uracal, cisto e seio uracal (Elias Junior et al., 2000). Nos animais podem ser observadas as mesmas alterações (Waldron, 1998).

$\mathrm{Na}$ persistência, o canal do uraco apresenta-se desobstruído após o nascimento (Lulich et al., 1997; Waldron, 1998) e, em conseqüência, ocorre eliminação de urina através do umbigo durante o armazenamento, ou ainda, expulsão da urina através do umbigo e uretra durante a micção (Lulich et al., 1997). Em geral, essa anormalidade é detectada ao nascimento e está associada a outras más formações do trato urogenital, como o refluxo vésico-ureteral e a ectopia renal (McCrystal et al., 2001). 
Tem-se observado que animais que apresentam essa afecção são mais susceptíveis às infecções bacterianas da vesícula urinária (Blood e Henderson, 1978; Confer e Panciera, 1990; Lulich et al., 1997; Waldron, 1998) e que devido à dificuldade de cicatrização do umbigo, em muitos casos desenvolve-se uma onfaloflebite (Blood e Henderson, 1978; Novoa et al., 2004).

A persistência do uraco é uma alteração congênita pouco observada na prática veterinária de pequenos animais e esporadicamente relatada na literatura. Os potros são citados como os mais acometidos (Hansen, 1972; Blood e Henderson, 1978; Confer e Panciera, 1990).

Nos felinos esse defeito é raro, sendo mais comum a presença de divertículos, que são detectados com certa freqüência em gatos que apresentam disfunção do trato urinário inferior, principalmente, obstrução uretral (Waldron, 1998).

O diagnóstico da afecção baseia-se nos achados da história clínica, sintomas, exame físico, procedimentos laboratoriais e deve ser confirmado mediante procedimentos radiográficos contrastados (Lulich et al., 1997; Waldron, 1998).

O objetivo deste trabalho foi descrever um caso de persistência do uraco em um gato de cinco meses de idade, por se tratar de um defeito congênito raro na referida espécie, principalmente, na idade em que foi detectado, dando um enfoque aos meios disponíveis para diagnosticar a afecção.

\section{CASUÍSTICA}

Um gato, sem raça definida, de aproximadamente cinco meses, foi atendido no hospital veterinário, com histórico de estar urinando através da cicatriz umbilical há uma semana.

Ao exame clínico constatou-se que o paciente eliminava urina através do umbigo, principalmente quando se realizava a compressão manual da vesícula urinária. Pôde-se detectar a presença de uma fístula no centro do umbigo, por onde escoava urina e, ainda, que a área circunvizinha se encontrava hiperêmica. O esforço para urinar era evidente e sempre estava acompanhado por grunhidos e contrações abdominais. Como exames complementares foram realizados a urinálise, ultra-sonografia e radiografias simples e contrastada do trato urinário inferior.

Após a cistografia, utilizando $10 \mathrm{ml}$ de um contraste à base de ioxitalamato de meglumina e de sódio ${ }^{1}$, e durante o procedimento cirúrgico, foi possível confirmar a suspeita diagnóstica de persistência do uraco.

O protocolo anestésico escolhido para a realização do procedimento cirúrgico constou de medicação pré-anestésica com sulfato de atropina $^{2}(0,044 \mathrm{mg} / \mathrm{kg})$ e cloridrato de xilazina ${ }^{3}$ $(0,5 \mathrm{mg} / \mathrm{kg})$ pela via intramuscular (IM), indução e manutenção com propofol ${ }^{4}(3 \mathrm{mg} / \mathrm{kg})$ pela via intravenosa (IV). A antibioticoterapia foi realizada mediante administração de cefalotina sódica $^{5}(25 \mathrm{mg} / \mathrm{kg}, \mathrm{IV})$.

Após a indução anestésica e tricotomia ampla do abdômen, o paciente foi posicionado na mesa cirúrgica em decúbito dorsal. Seguido à antisepsia do campo operatório com álcool a $70 \%{ }^{6} \mathrm{e}$ gluconato de clorexidine a $2 \%{ }^{7}$, os campos cirúrgicos foram fixados e procedeu-se a abertura da cavidade abdominal por meio de uma incisão retroumbilical na linha média do abdômen. A abertura da cavidade levou à exposição da vesícula urinária e do uraco (Fig. 1), caracterizado como um prolongamento tubular de aproximadamente $2 \mathrm{~cm}$ de comprimento e $1 \mathrm{~cm}$ de largura.

A dissecação do canal uracal foi realizada por meio de manobras delicadas, seccionando-se o uraco desde a sua inserção no umbigo (Fig. 2) até a sua junção com a vesícula urinária (Fig. 3).

\footnotetext{
${ }^{1}$ Ioxitalamato de meglumina e de sódio: Telebrix ${ }^{\circledR}$ - Guerbet Rio de Janeiro, RJ.

${ }^{2}$ Sulfato de atropina: Sulfato de atropina ${ }^{\circledR}$ solução injetável Brasmedica S. A. - São Paulo, SP.

${ }^{3}$ Cloridrato de xilazina: Anasedan ${ }^{\circledR}$ solução injetável -

Vetbrands - Jacareí, SP.

${ }^{4}$ Propofol: Propovan ${ }^{\circledR}$ solução injetável - Cristália - Itapira, SP.

${ }^{5}$ Cefalotina sódica: Cefalotina sódica ${ }^{\circledR}$ - Eurofarma - São Paulo, SP.

${ }^{6}$ Álcool a 70\%: Hi-álcool $70^{\circledR}$ - Halex Istar - Goiânia, GO.

${ }^{7}$ Gluconato de clorexidine a $2 \%$ : Riohex ${ }^{\circledR}$ - Bioquímica - São José do Rio Preto, SP
} 
A vesícula urinária foi suturada nas camadas seromuscular com padrão contínuo invertido (Cushing seguido por Lambert), utilizando fio de poliglactina ${ }^{8} 3-0$. A síntese da parede abdominal foi realizada na linha alba com pontos isolados simples utilizando fio de nylon ${ }^{9} 3-0$, seguido da aproximação da tela subcutânea e fechamento da pele, com categute cromado ${ }^{10}$ 3-0 em ziguezague subcutâneo e mononylon ${ }^{11}$ 3-0 em sutura intradérmica, respectivamente. A ferida cirúrgica foi protegida com micropore, após limpeza e anti-sepsia da região com tintura de benjoim ${ }^{12}$.

No período pós-operatório, foi prescrita terapia antiinflamatória e antibiótica, com ketoprofeno comprimido $^{13}$ e cefalexina solução oral ${ }^{14}$.

Após oito dias de cirurgia, o paciente regressou ao hospital veterinário para avaliação clínico-cirúrgica e retirada dos pontos. O pós-operatório transcorreu sem complicações e o paciente urinou normalmente através da uretra.

\section{DISCUSSÃO}

A persistência uracal é uma condição rara em pequenos animais, especialmente na espécie felina e, conseqüentemente, a literatura referente ao assunto é escassa.

O fato de o paciente eliminar urina através da cicatriz umbilical apenas com cinco meses de idade pode ser considerado um acontecimento atípico, uma vez que animais com persistência do uraco demonstram esse sinal desde os primeiros dias de vida, por se tratar de uma alteração congênita. Acredita-se que isso foi resultado de um aumento na pressão local, que ocasionou a maior abertura do canal. Essa observação confirma os achados de Lulich et al. (1997), que citam que o aumento da pressão na vesícula urinária poderá levar à conversão de um canal uracal fechado, em um uraco pérvio.

\footnotetext{
${ }^{8}$ Fio de poliglactina 910: Vicryl ${ }^{\circledR}$ - Ethicon - São José dos Campos, SP

9 Fio de nylon: Nylon ${ }^{\circledR}$ - Ethicon - São José dos Campos, SP

${ }^{10}$ Fio de categute cromado: Categute cromado ${ }^{\circledR}$ - Ethicon São José dos Campos, SP

${ }^{11}$ Fio de mononylon: Mononylon ${ }^{\circledR}$ - Ethicon - São José dos Campos, SP

12 Tintura de Benjoim $^{\circledR}$ - Farmax - Divinópolis, MG

13 Ketoprofeno: Ketofen ${ }^{\circledR}$ comprimido 5 mg - Merial Saúde Animal Ltda.- Campinas, SP

${ }^{14}$ Cefalexina: Cefalexina ${ }^{\circledR}$ solução oral $125 \mathrm{mg} / 5 \mathrm{ml}$ - Neo Química - Anápolis, GO
}

Uma das primeiras observações realizadas durante o exame clínico foi a presença de disúria e esforço para urinar, além do moderado aumento da vesícula urinária, evidente mediante palpação do abdômen. De acordo com Blood e Henderson (1978), a dor abdominal pode acontecer na presença de obstrução uretral e distensão da bexiga.

O número de leucócitos por campo ( 5 a 7) no sumário de urina confirmou a suspeita de inflamação do trato urinário inferior, pois de acordo com Meyer et al.(1995), o aumento no número dessas células (acima de 3 por campo) indica a presença de processo inflamatório. Outros indícios que sugeriram cistite foram a grande presença de proteínas, filamentos de muco, hemácias e células epiteliais de descamação na amostra.

Durante a interpretação da cistografia foi observado o preenchimento do canal uracal pelo contraste, sendo possível acompanhar todo seu trajeto, desde a face crânio-ventral da vesícula urinária, até o umbigo (Fig. 4). Também foi possível confirmar a presença de cistite, pela evidência de irregularidade da mucosa. Lulich et al. (1997) afirmaram que a radiografia é uma técnica diagnóstica valiosa para os distúrbios do trato urinário inferior, contudo, a necessidade de realizar procedimentos contrastados, como afirmou Waldron (1998), é realmente indispensável em determinados casos. No episódio relatado, nada pode ser confirmado antes da realização da técnica contrastada.

Na ultra-sonografia foi observado espessamento e irregularidade da parede da vesícula urinária, sugestivo de inflamação. Waldron (1998) citou que esse exame deve servir de auxílio para os estudos radiográficos durante a avaliação da bexiga.

O procedimento cirúrgico transcorreu sem complicações e seguindo as recomendações de Waldron (1998). Além da ressecção do canal uracal, uma porção da vesícula urinária e a cicatriz umbilical também foram removidas.

Conclui-se que o procedimento cirúrgico realizado para remoção do uraco persistente foi bem sucedido, visto que o paciente voltou a urinar fisiologicamente, e que exames complementares, em especial a cistografia, são indispensáveis para o diagnóstico dessa rara afecção. 


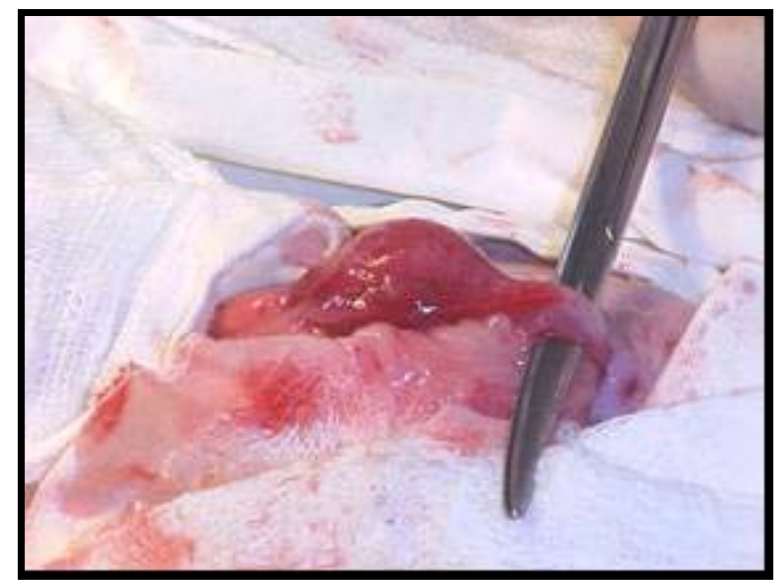

Figura 1. Ducto uracal sendo aparado por uma tesoura de metzembaum em gato.

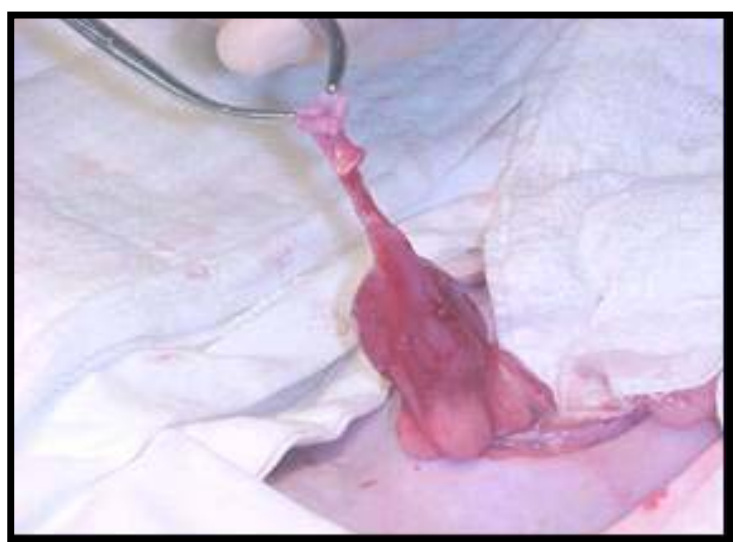

Figura 2. Porção distal do uraco seccionada em gato.

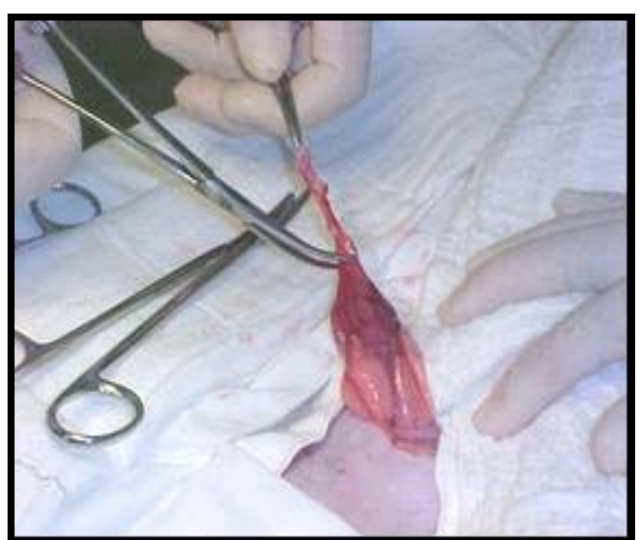

Figura 3. Preparo para a remoção da porção cranial do uraco inserido no ápice da vesícula urinária em gato.

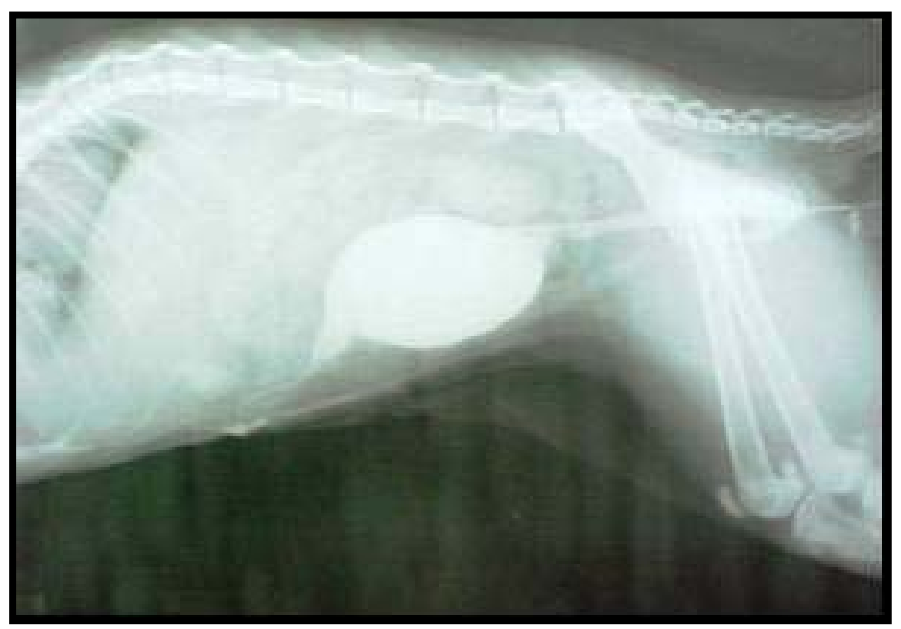

Figura 4. Projeção lateral da cavidade abdominal, onde se visibiliza o canal uracal, após a realização da cistografia, em gato. 


\section{REFERÊNCIAS BIBLIOGRÁFICAS}

BLOOD, D.C.; HENDERSON, J.A. Doença do sistema urinário. In: _. Medicina Veterinária. 4.ed. Rio de Janeiro: Guanabara Koogan, 1978. p.161-176.

CONFER, A.W.; PANCIERA, R.J. Sistema urinário. In: THOMSON, R.G. Patologia veterinária especial. São Paulo: Manole, 1990. p.497-530.

ELIAS JUNIOR, A.M.; OKANO, N.; VARGAS, E.C. et al. Persistência do uraco. Acta Cir. Bras., v.15, p.101-101, 2000.

HANSEN, J.S. Patent urachus in a cat (a case history). Vet. Med. Small Anim. Clin., v.67, p.379-381, 1972.

HANSEN, J.S. Urachus remnant in the cat: occurrence and relationship to the feline urological syndrome. Vet. Med. Small Anim. Clin., v.72, p.1735-1746, 1977.

LULICH, J.P.; OSBORNE, C.A.; BARTGES, J.W. et al. Afecções do trato urinário inferior dos caninos. In: ETTINGER, S.J.; FELDMAN, E.C. (Eds). Tratado de medicina veterinária: moléstias do cão e do gato. 4.ed. São Paulo: Manole, 1997. p.2535-2573.

McCRYSTAL, D.J.; EWING, M.J.; LAMBRIANIDES, A.L. Acquired urachal pathology: presentation of five cases and a review of the literature. ANZ J. Surg., n.71, p.774-776, 2001.

MEYER, D.J.; COLES, E.H.; RICH, L.J. Anormalidades em testes do trato urinário. In: . Medicina de laboratório veterinário: interpretação e diagnóstico. São Paulo: Roca, 1995. p.63-72.

NOVOA, A.; IORCANSKY, S.; ROSENZWEIG, S. El pediatra ante un lactante com caída tardía del cordón umbilical. Arch. Arg. Ped., v.102, p.203-207, 2004.

OSBORNE, C.A.; KRUGER, J.M.; LULICH, J.P. et al. Afecções do trato urinário inferior dos felinos. In: ETTINGER, S.J.; FELDMAN, E.C. Tratado de medicina veterinária: moléstias do cão e do gato. 4.ed. São Paulo: Manole, 1997. 140, p.2496-2534.

WALDRON, D.R. Bexiga. In: SLATTER, D. Manual de cirurgia de pequenos animais. 2.ed. São Paulo: Manole, 1998. p. 1723-1736. 